\title{
Managing Student Drop-Outs
}

William B. Joyce, (Email: wbjoyce@eiu,edu), Eastern Illinois College

\begin{abstract}
This study investigates the efficacy of several variables used to predict voluntary, organizationally avoidable turnover even before the student becomes enrolled in a college. Analyses conducted on student applicant data collected in 2 separate colleges confirmed that bio-data, clear-purpose attitudes and intentions, and disguised-purpose dispositional retention scales predicted voluntary, avoidable turnover.

Results also revealed that bio-data scales and disguised-purpose retention scales added incremental validity, whereas clear-purpose retention scales did not explain significant incremental variance in turnover beyond what was explained by bio-data and the disguised-purpose scales. Furthermore, disparate impact was consistently small.
\end{abstract}

\section{INTRODUCTION}

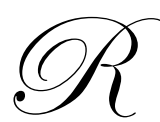

esearchers and educators alike are interested in explaining student drop-outs. Administrators are concerned primarily because of the personnel costs incurred when students voluntarily quit. Scholars are interested in turnover because it is an important criterion and reflects a critical motivated behavior, one that may provide insight into volitional behavior. Employee turnover has been extensively researched, and most of this research has focused on understanding why employees leave once they are in a organization. In contrast, there has been little research investigating whether colleges can reduce turnover at selection. Most of the research related to preventing turnover before employees start their careers centers on whether realistic organizational previews reduce turnover by providing applicants an accurate glimpse of both the favorable and unfavorable aspects of the organization before they begin employment (Rynes, 1991; Wanous and Collela, 1989). A recent meta-analysis (Phillips, 1998) revealed only modest effect sizes for realistic job previews when predicting voluntary turnover. Thus, the purpose of this study was to systematically explore whether student applicants with high turnover propensities can be identified prior to college entry. Three sets of predictors that are particularly promising for selection purposes are discussed next.

\section{Bio-Data}

Bio-data inventories tend to be very good predictors of turnover (Griffeth, Horn, and Gaertner, 2000). However, there are also disadvantages associated with using bio-data. Researchers find that the theoretical nature of empirically keyed bio-data items limits their ability to understand why students leave their colleges. Practitioners are concerned about bio-data items for fear of discrimination and lawsuits (Gatewood and Feild, 1987). Some of the most predictive bio-data items are related to age, gender, or race, which prevents these questions from being used (Rothstein, Schmidt, Erwin, Owens, and Sparks, 1990; and Schmidt and Hunter, 1998). To address these issues, researchers have emphasized the need to develop a theoretical basis for studying bio-data items (Dean, Russell, and Muchirisky, 1999; Pace and Schoenfeldt, 1977).

Bio-data items assessing whether a student applicant was referred by a current student or has friends or family enrolled at the college have their theoretical basis tied to the realistic school-preview literature and the concept of being embedded at a school (Breaugh and Dossett, 1989; Mitchell, Holtom, Lee, Sablynski, and Erez, 2001). Student applicants with more contacts within the organization are apt to better understand the nature of being a student and the college. A more realistic view may provide a "vaccination effect" that lowers expectations, thereby preventing educational dissatisfaction and turnover (Phillips, 1998). Furthermore, students referring an applicant to apply at the college may be less likely to refer student applicants who are less capable or those who would not fit as well with the college's culture (Breaugh and Starke, 2000; Rynes, 1991). Latham and Leddy (1987) found that 
students who were referred had higher levels of educational involvement, educational satisfaction, and college commitment than students who were unsolicited or responded to newspaper advertising. Related to the theory of being embedded in education (Mitchell et al., 2001) is the finding that having friends or family within the college prior to enrollment is likely to strengthen the student's commitment to the firm and reduce the likelihood that he or she will leave. Empirical support for these suppositions is provided in three studies. Breaugh and Dossett (1989) found that whether the student applicant has friends or relatives enrolled at the college was a significant predictor of turnover. Similarly, Breaugh and Mann (1984) found that student referrals were a relevant predictor of turnover. Bernardin (1987) also included items related to having friends or relatives enrolled at the college, as well as student referrals, in his application blank that was used to predict student turnover. These results suggest the value of these predictors.

Tenure at a previous college, for example a community college for transfer students, is based on the theory that past behavior may be the best predictor of future behavior (Owens and Schoenfeldt, 1979); and Wernimont and Campbell, 1968). If a student has a habit of seeking out other colleges, as represented by short tenure at the previous college, he or she is likely to do so again. Also, short tenure at the previous school may reflect a lower work ethic, which is correlated with college commitment and turnover (Mathieu and Zajac, 1990). Cascio (1976) found that tenure at a previous college, as pant of a weighted application blank, was predictive of turnover. These results suggest that students who have shown a propensity to rapidly quit other colleges are apt to repeat these behaviors in the future. On the basis of their practical and theoretical relevance, the following hypotheses for these three bio-data items are proposed:

Hypothesis 1: Students who had a longer tenure with their immediate former college will be more apt to stay with their current college than students who had a shorter tenure with their previous colleges.

Hypothesis 2: Students who were referred by current students will be more likely to remain with their current colleges.

Hypothesis 3: The more friends and family students had at the current college at the time of enrollment, the more likely they are to remain.

\section{ATTITUDE AND BEHAVIORAL INTENTIONS}

Considerable attention has been paid to the role that scholastic attitudes and behavioral intentions play in turnover (Griffeth et al., 2000; and Tett and Meyer, 1993). Scholastic attitudes about both school in general and college specifically, along with cognitions about intent to quit after the student is enrolled (Tett and Meyer, 1993), are important predictors of turnover. However, student applicant attitudes and intentions toward school in general, the college specifically, and education in general before being enrolled may be predictive of turnover as well. Research suggests that most students have developed attitudes about their educational program for which they are applying before they start school (Hom and Griffeth, 1995). Consequently, attitudes and intentions prior to enrollment warrant consideration as important predictors of voluntary turnover. In this study, focus is on those variables that prior research has shown are related to turnover for current students (Griffeth et al., 2000) yet are also expected to be predictive for student applicants.

Assessing student applicant attitudes and intentions (for example, with questions such as "Are you committed to this college?" and "Do you plan to quit") prior to enrollment is fraught with difficulties. An important issue is that of potential response distortion by student applicants, including the possibility of faking, responding in a socially desirable manner, or otherwise responding inaccurately. Recent research on the utility of integrity tests for selection purposes has important implications for this study (Ones, Viswesvaran, and Schmidt, 1993). An essential finding is that integrity tests can be classified into two categories: (a) clear-purpose integrity tests and (b) disguised-purpose integrity tests (Sackett, Burris, and Callahan, 1989). Clear-purpose tests are designed to directly assess attitudes regarding the criterion of interest (for example, "Do you cheatl?). Disguised-purpose tests are considerably broader in focus and are not explicitly aimed at the criterion (for example, "Do you like to take chances"). Such a test is less obvious to the respondent largely because the items only indirectly relate to the criterion. This study examines both types of scales to determine whether this distinction is also critical when predicting turnover. 
Two clear-purpose scales that directly assess the student applicant's turnover-related attitudes and intentions to college study are examined. The first is intent to quit. Intent to quit is one of the best, if not the best, predictors of turnover (Griffeth et al., 2000). This is not surprising, as the intent to perform a behavior is often found to be the best predictor of that behavior (Fishbein and Ajzen, 1975). Intent by the applicant to quit their studies before even starting the new college may also be an effective predictor of turnover. Student applicants may plan on leaving the college in a short time for several reasons. For example, they may be waiting until a more suitable college, or they may be intending to find a permanent career unrelated to their college education. The unfolding model of turnover (Lee, Mitchell, Haltom, McDaniel, and Hill, 1999) suggests that these turnover cognitions, or "scripts to quit," are often formed early, even before college enrollment. For these reasons, intent to quit is likely to be an important predictor of turnover, even when assessed before enrollment.

Hypothesis 4: Students who have a greater intent to quit prior to enrollment will be more apt to do so than those who are not intending to quit.

How much the student applicant desires the enrollment is also likely to be an important predictor of turnover (Mowday, Porter, and Steers, 1982). A new student with a strong desire to be educated at the college will require less time to be assimilated into the college's culture (Van Maanen and Schein, 1979) and is likely to have greater psychological identification with the college (Kanungo, 1982; Lee et al., 992; and Mael and Ashforth, 1995). Evidence suggests that current students who feel more involved with their colleges are less likely to leave (Hom \& Griffeth, 1995). Similarly, it is expected that newly enrolled students with a stronger desire for the college would be more likely to maintain enrollment at the college.

Hypothesis 5: Students with a greater desire for the educational program and college will be less likely to quit than those who do not have as much desire for the educational program and college.

\section{DISPOSITIONS}

Two disguised-purpose dispositional scales expected to have important relationships with turnover are selfconfidence and decisiveness. Lee et al. (1992) noted that students with high self-confidence should respond more favorably to the challenges of a new environment. They found that confidence, as a component of their commitmentpropensity composite, significantly predicted organizational commitment one-year after joining the Air Force Academy and, in turn, commitment significantly predicted turnover, Hom and Griffeth (1995) also reported that selfconfidence based on job accomplishments predicted turnover. Furthermore, Parsons, Herold, and Leatherwood (1985) showed that new students with higher confidence in their abilities were less likely to quit than those who attributed their performance to luck. On the basis of these findings, it is expected that student applicants with higher selfconfidence would be more

persistent in striving to adapt to novel educational demands or college settings and less likely to withdraw from college because of anxiety from low performance or ineffective adjustment.

Hypothesis 6: Students with higher self-confidence will be more likely to stay enrolled with the college than those with lower self-confidence.

Decisiveness reflects the second disguised-purpose retention predictor examined in this article. Decisive students give more deliberation to important decisions than do indecisive individuals, and consequently are likely to be more committed to those decisions and less likely to leave the organization (Hom and Griffeth, 1995; Lee et al., 1992; and Salancik, 1977). Decisiveness is a component of the personality trait of conscientiousness, which is also related to turnover (Barrick and Mount, 1996; and Barrick, Mount, and Strauss, 1994). Horn and Griffeth (1995) found support for decisiveness as an antecedent to commitment, which directly affects organizational commitment and, indirectly, turnover.

Hypothesis 7: Students who are more decisive will be more apt to stay in college than those students who are not as decisive. 


\section{METHOD}

\section{Participants and Procedure}

The sample consisted of 566 student applicants in two separate colleges at two separate colleges in the Midwest; 219 individuals were enrolled at a more northern college (Study 1), and the remaining 347 were enrolled at a more southern college (Study 2). However, 60 students (Study 1, N = 28; Study 2, N = 32) involuntarily left the colleges (for example, expelled for lack of academic progress and for counter-productive behavior, etc.) during the study, and 61 students (Study 1, N = 15; Study 2, N = 46) voluntarily, unavoidably left the college (for example, family conflicts, child care, return to work, etc.). After removing the 121 students who left for involuntary or voluntary, unavoidable reasons, the actual sample was a total of 445 student applicants (Study 1, N = 176; Study 2, N = 269). The average age of the student applicants in Study 1 was 19 years; $66 \%$ of the applicants were women, $67 \%$ were White, $23 \%$ were Black, $5 \%$ were Hispanic, and another $5 \%$ were categorized as "other." In Study 2, the average age of the applicants was 17 years; $59 \%$ of the applicants were men, $68 \%$ were White, $22 \%$ were Hispanic, and $9 \%$ were Black. As part of the enrollment process, participants completed a study styles survey (which comprised the scales outlined below) as actual applicants. Although the surveys were not used for enrollment decisions, when participants completed the survey as applicants, they believed it would affect whether they were enrolled.

\section{Measures}

With respect to biographical measures, the number of months the student was enrolled at his or her most recent school represented the best theoretically relevant biographical item, time at prior college.

The second biographical measure, number of friends and family, asked the student applicant in two questions the number of friends and relatives enrolled at the college. To measure the total number of existing relationships at the college, the sum across both questions was used to reflect the number of friend and family variable. Student reference was the third biographical measure. It asked whether the student applicant had been referred by another student of the college.

Attitudes and behavioral intentions were measured with pre-enrollment clear-purpose retention scales. Desire for enrollment was assessed with seven items from the Lee et al. (1992) Desirability Scale (0.76 in Study 1 and 0.82 in Study 2).

Overt intent to stay was assessed with four items from Chatmag (1991); 80 in Study 1, and 0.75 in Study 2). A scale ranging from 1 (strongly disagree) to 5 (strongly agree) was used.

Pre-enrollment dispositions were measured with disguised-purpose retention scales. Self-confidence was assessed with eight items from Lee et al. (1992; 0.74 in Study 1 and 0.82 in Study 2). Decisiveness was measured with a 5-item scale adapted from Lee et al. (1992; 0.87 in Study 1 and 0.73 in Study 2); items were reverse scored. The same 5-point response scale mentioned above was used for both scales.

Voluntary, college avoidable turnover was measured by collecting data for a period of 6 months after the student was enrolled. Consistent with Abelson's (1987) model, both organizations categorized turnover into whether the turnover was voluntary or involuntary from the student's perspective and avoidable or unavoidable from the college's perspective. There were two turnover categories of interest: (a) 228 students who stayed with the college (Study 1, N = 118; and Study 2, N = 110) and (b) 217 students who left for voluntary, college avoidable reasons (Study 1, N = 58; Study 2, N = 159). The latter category refers to turnover that reflected the student's choice to leave and turnover the college may have been able to avoid (for example, through financial aid). College-related unavoidable turnover (for example, dropping out to follow a relocating spouse) was not of primary interest because these leavers did not withdraw because of dissatisfaction with the college. Abelson (1987) found that students who leave the college for unavoidable reasons are more similar attitudinally to people who stay than to those who leave for college avoidable reasons (for example, better financial aid). Thus, college unavoidable turnover is likely not as affected by individual psychological differences and therefore not as well explained by the measures assessed. In fact, 
Hom and Griffeth (1995) concluded that college-related avoidable (versus unavoidable) turnover is considered a superior criterion for testing prevailing turnover models. To ensure that the criterion used is the most theoretically appropriate, the focus was on voluntary, college-related avoidable turnover. However, to enhance comparability to prior findings, also reported is the correlations with voluntary turnover. Exit surveys were used to identify the reason for turnover.

Because turnover was an important issue for both colleges, faculty and administrators met weekly to identify the reason for turnover for each student who left the college during this study. In addition, department chairs or college advisors conducted exit interviews (including phone interviews) with the departing students, and this input was provided at the enrollment/retention meetings. Thus, the student records reflected knowledge about the reasons for turnover from the chairs' and advisors' perspectives as well as from the students. Because the chairs ultimately recorded the reasons, they made the final determination of whether there was a disagreement about the reasons for turnover. In these records, the reasons for turnover were categorized into specific reasons (for example, turnover due to cheating or other conduct-related issues), which were then coded as voluntary or involuntary and as college avoidable or unavoidable. This method of triangulation is consistent with recommendations from the turnover research (Mobley, Griffeth, Hand, and Meglino, 1979), as is the coding of what constitutes each category of turnover (Abelson, 1987). Taken together, it is believed that the student records reporting reasons for turnover were accurate.

\section{RESULTS}

The means, standard deviations, and correlations among all variables are presented in Appendix One. The correlations reported in Appendix One are the sample-weighted average correlations from both studies. In this analysis, none of the correlations between predictors and voluntary, organizationally avoidable turnover differed across the two samples (the largest difference in correlations across the two samples was a difference of 0.06 for number of friends and family with turnover). Given that these differences are not meaningful, the best estimate is the combined, sample-weighted correlation. This is reported in Appendix One.

As hypothesized, all predictors were negatively related to voluntary, college-related avoidable turnover (range from -0.16 to -0.22 ). The correlations with voluntary turnover also are reported in Appendix One. These results are included to provide a comparison with prior research. However, because of the reasons stated earlier, voluntary, avoidable turnover was viewed as the more relevant criterion, and the remainder of the discussion focuses on this outcome.

An important purpose of this study was to establish the incremental validity of these theoretically relevant predictors of turn-over. Hierarchical regression analyses was used to test the ability of each set of predictors (biodata, clear-purpose attitudes and intention scales, and disguised-purpose dispositional scales) to explain separate portions of the variance in voluntary, college-related, avoidable turnover. Results from both analyses and a sample weighted combined estimate are summarized in Appendix Two. Rather than report analyses for all combinations, biodata were entered first and last to illustrate the magnitude of effects observed from the most established set of predictors. The disguised-purpose dispositional variables were entered second, as these measures would be preferred, all else equal, to clear-purpose attitudes and intentions because they are less subject to bias from social desirability. For each equation, there was an assessment of the overall variance accounted for (R-squared), the adjusted R-squared, and the relative change in prediction ( $\square$ R-squared) obtained by adding the set of variables for each step of that regression. Thus, the relative change ( $\square$ R-squared) demonstrates the incremental gain of that predictor set, once all prior sets (steps) of variables are included in the regression.

The overall regression equation for voluntary, college-related avoidable turnover is significant in both studies ( $\mathrm{R}$-squares $=0.36$ and 0.37$)$ and in the combined sample $(\mathrm{R}$-squared $=0.37)$. As shown in appendix two, including the biographical variable set either first or last increases the multiple correlation substantially ( $\square \mathrm{R}$-squared of 0.10 to 0.12 even in Step 3). Although the-disguised-purpose dispositional scales add to bio-data when predicting turnover ( $\square$ R-squared $=0.05$, Step 2), the clear-purpose attitudes and intentions scales did not significantly add incremental validity to either measures of disguised-purpose retention predictors or biographical variables. Finally, although the overall prediction of all sets of variables incrementally adds to the prediction of voluntary, avoidable turnover, over 
each set alone (biographical, disguised, or clear-purpose retention scales), the overall regression provides almost no gain in prediction over a multiple correlation derived from using disguised-purpose dispositional retention predictors (self-confidence, decisiveness) and the biographical variables (student reference, number of friends and family, and time at prior college; Step $2 \mathrm{R}$-squared $=0.36$ versus Step $3 \mathrm{R}$-squared $=0.37$ ). The evidence demonstrates that the clear-purpose measures of retention (desire for enrollment at the college, intent to stay) do not consistently add to the prediction of voluntary, college-related avoidable turnover beyond that accounted for by disguised-purpose dispositional retention scales and bio-data variables.

To ensure that these results were not influenced by the use of a binary dependent variable, logistic regressions were also conducted. The results when voluntary, avoidable turnover was logistically regressed onto these predictors are presented in Appendix Three. Regardless of whether the bio-data measures were entered first or last, the model and block chi-square $(\chi 2)$ was significant, indicating that the model represents a significant improvement over a model containing either only the constant or all other sets of variables. Furthermore, across both studies the model and block chi-squares are significant when entering the disguised-purpose scales. Thus, these analyses demonstrate that the results reported in appendix two are supported even when a nonlinear logistic regression-estimation technique is used. It is not surprising that these analyses reported similar results, because turnover rates (33\% and 59\%, respectively) fell into the range of probabilities (30\%-70\%) where ordinary least squares regression and logistic regression yield similar results (Huselid and Day, 1991).

Because researchers, educators, and administrators are interested in the likely disparate impact for these predictors, the effect size of subgroup differences of applicants were examined. In Appendix Four, the standardized difference (d score) among various subgroups associated with the different predictors is presented. Across race, gender, and age subgroup comparisons, the mean differences are quite small. Furthermore, in over half of the cases (54\%), the minority group scored higher than the majority group. For example, although Whites were somewhat more likely to receive a student reference than either Hispanics or Blacks ( 0.10 and 0.04 , respectively), members from both minority groups were more likely to have friends and family enrolled at the college $(-0.22$ and -0.15 , respectively, for Hispanics and Blacks). Although the differences are not large, it should be noted that the effect size was slightly larger when the predictor favored the minority group over the majority group. For the 16 instances when the majority group scored higher than the minority group, the average $\mathrm{d}$ score was 0.12 . However, when the minority group scored higher than the majority group, the average $\mathrm{d}$-score was -0.22 . The largest $\mathrm{d}$ score was -0.43 for months enrolled at the last college, indicating that older students tended to have longer tenure with their previous colleges. The results show that these predictors have high validity, yet their use in selection decisions is likely to lead to low levels of adverse impact.

\section{DISCUSSION}

This study provides additional evidence that theoretically relevant bio-data, clear-purpose attitudes and intentions, and disguised-purpose dispositions related to retention predict voluntary, college-related avoidable turnover. Turnover researchers have rarely examined this question with actual student enrollments (Griffeth et al., 2000), and never have with this particular set of predictors. Overall the results revealed that pre-enrollment dispositions, attitudes, and behavioral intentions predicted voluntary, college-related avoidable turnover, whether it was assessed with clear-purpose retention scales or disguised-purpose retention scales. The results also supported prior findings (Horn and Griffeth, 1995) that bio-data is an important predictor of turnover. This study extends previous work by examining the incremental validity of these bio-data predictors beyond the variance explained by the attitudes, intentions, and dispositions measured in this study. Similar to other non-cognitive predictors (Feingold, 1994; and Schmitt et al., 1997), the results also provide some assurances that colleges using these predictors would not incur adverse impact based on age, race, or gender.

This study brings these variables together for the first time in determining their joint ability to predict turnover before enrollment. With the bio-data and disguised-purpose dispositional retention scales having moderate correlations with turnover and little overlap with each other, these predictors both added significant amounts of incremental variance in turnover, beyond the variance accounted for by the other set of variables or the clear-purpose attitude and intention scales. These results illustrate that theoretically relevant bio-data and college-related dispositions assessed prior to enrollment can predict who is likely to leave or remain with the college. The finding that 
clear-purpose attitude and intention scales offer little additional predictive ability over disguised-purpose dispositions is an interesting one. For current students, these constructs, particularly intent to quit or drop-out, are among the best predictors of voluntary turnover. The results indicate that these measures may not be as predictive when student applicants provide the responses. This likely is because student applicants have less information on which to base their attitudes and intentions. For example, neither college used realistic enrollment previews in this study, which may limit the amount of information student applicants had about the colleges. This may explain why the clear-purpose scales were not better predictors of turnover in this setting.

The results provide evidence that researchers, educators, and administrators would substantially benefit from adding these types of measures, particularly disguised-purpose dispositional scales, to selection batteries designed to reduce turnover and drop-outs. These findings differ from those reported in the integrity literature, where clearpurpose scales tend to predict the criteria of interest (for example, counterproductive behaviors) better than the disguised-purpose predictors (Ones et al., 1993). This difference may be because the clear-purpose constructs assessed in this study were attitudes and intentions specific to the target college, and clear-purpose integrity tests directly assess attitudes and beliefs about theft or honesty, which are not specific to the firm. Finally, although this study was not able to assess the effects of a realistic enrollment preview in either study, our zero-order correlations and composite validities are substantially larger than those reported for realistic enrollment previews (ranging from 0.16 to -0.22 and adjusted $\mathrm{R}$-squared $=0.33$ versus mean adjusted $\mathrm{R}$-squared $=-0.09$ for realistic enrollment previews). These results illustrate the value researchers, educators, and administrators may realize if they (and future researchers) expand their thinking beyond realistic enrollment previews and bio-data to other predictors of turnover, including pre-enrollment retention-related dispositions, altitudes, and intentions.

The use of three distinct sets of individual differences also adds to the empirical evidence supporting theoretical models of turnover and drop-outs. Understanding that differences in pre-enrollment attitudes, dispositions, and background histories influence future turnover decisions provides researchers with a foundation on which to examine how these individual differences work through college satisfaction and college commitment to predict turnover. Specifically, the predictors examined in this study (for example, self-confidence, decisiveness, desire for enrollment, and intent to stay) fit within many turnover/drop-out models. These results provide turnover/drop-out researchers with more individual differences to include in future research, some of which should be assessed before the student is enrolled.

A revealing finding is that although most turnover/drop-out models place intent to quit/drop-out just before actual turnover, the results of this study show that some students may intend to quit/drop-out even before starting school. The construct of intent to quit may need to be alternatively conceptualized as a decision that is not just affected by what students find out about the program and college once they are enrolled but also as a decision that may be made even before they start their college careers. These findings suggest that where intent to quit/drop-out is placed in a model of turnover is in part dependent on whether it is assessed before or after college entry.

One of the strengths of this study is the use of two independent samples to examine the relationship between the student attributes of interest and turnover. Although both sample sizes offer consistent estimates of the variables studied (Study 1, N = 176; Study 2, N = 269), the combined pool of 445 actual student applicants offers a large sample from which to draw conclusions about the data. The use of two samples of lower-division enrollment (the first of white-collar women with almost a quarter black participants and the second of mostly blue-collar men with nearly a quarter Hispanic participants) may also increase the findings may be generalized.

One limitation is the possibility that student candidates engage in impression management, which may attenuate the correlation between individual student differences and turnover (Bernardin, 1987). For example, the intent-to-stay item "If I have my own way, I will be enrolled at this college six months from now" could be readily affected by social desirability. Student applicants striving to look better may innate the clear-purpose scales more than the disguised-purpose scales. This could also explain the lower predictive validities found for these scales in this study. Although past research has determined that social desirability does not affect the criterion-related validities of personality scales (Ones, Viswesvaran, and Reiss, 1996), future research might consider examining the effects of impression management on other measures, such as attitudes and behavioral intentions. 
Another limitation is that actual enrolling decisions were not made on the basis of these scores. An interesting question is whether the interpersonal dynamics of the college are significantly changed by enrolling only student applicants who intend to stay, desire the college, and are more decisive and confident. Specifically, is the college changed enough that the strength of the correlations reported in this study is also changed (beyond range restriction)? This is an important question for all turnover/drop-out research that reports relationships between predictors and turnover/drop-outs but does not actually implement the change in selecting the students.

This study also revealed that, contrary to expectations, the type of voluntary turnover did not differentially affect the predictive validities of the variables examined. In fact, the multiple correlation for voluntary turnover (Rsquared $=0.36$ ), which includes both unavoidable and avoidable turnover, was quite comparable to that reported for just voluntary, college-related avoidable turnover $(\mathrm{R}$-squared $=0.37)$. Although prior research has suggested that researchers should focus on quits/drop-outs that the college could have avoided (avoidable, voluntary turnover), these results do not support this distinction. First, it may be that the causes over which the college appears to have little control are not always unavoidable. For example, quitting to so that a spouse may return to school may actually be due to dissatisfaction with financial aide, which is an avoidable reason. Second, to avoid leaving the college under negative circumstances, students may disguise their real reasons for quitting/dropping-out by offering an unavoidable cause as justification. The deletion of such cases could eliminate some of the turnover variance that can be explained by avoidable turnover. Nevertheless, it should be noted that their omission did not weaken the predictive validity of the results obtained in this study. Future research may consider continuing to examine which type of voluntary turnover is most useful for explaining motivated behavior, perhaps by having former students contacted by a neutral third party who would keep reasons for turnover confidential.

The relationships between individual student differences and turnover are still not fully understood, particularly in selection contexts. This study shows that life history experiences, dispositions, attitudes, and behavioral intentions that are theoretically related to retention can serve as important predictors of voluntary, college-related avoidable turnover, even when these are assessed prior to hire. The results also reveal that disguised-purpose dispositional retention scales predicted voluntary, avoidable turnover slightly better than clear-purpose attitudes and intentions retention scales and added more incremental validity when used with bio-data predictors. These findings differ from those found in the integrity literature (Ones et al., 1993) and may warrant additional investigation. As almost all turnover models have individual student differences as antecedents to turnover, this study begins to fulfill the theoretical gaps in understanding the individual student attributes that predispose some students to quit/drop-out even before they become enrolled.

\section{Appendix One: Descriptive Statistics and Correlations}

Panel A

\begin{tabular}{|c|c|c|c|c|c|}
\hline \multirow{3}{*}{\multicolumn{2}{|c|}{ Variable }} & \multirow{2}{*}{\multicolumn{2}{|c|}{$\begin{array}{l}\text { Study } 1 \\
\mathbf{N}=176\end{array}$}} & \multirow{2}{*}{\multicolumn{2}{|c|}{$\begin{array}{l}\text { Study } 2 \\
N=269\end{array}$}} \\
\hline & & & & & \\
\hline & & Mean & SD & Mean & SD \\
\hline \multicolumn{6}{|c|}{ Bio-Data } \\
\hline 1. & Student Reference & 0.45 & 0.50 & 0.21 & 0.41 \\
\hline 2. & Number of Friends and Family & 1.44 & 0.84 & 1.98 & 3.38 \\
\hline 3. & Months at Other Colleges & 23.10 & 18.90 & 27.00 & 18.00 \\
\hline \multicolumn{6}{|c|}{ Clear-Purpose Attitudes and Intention Scales } \\
\hline 4. & Overt Intent to Stay & 15.97 & 2.91 & 15.30 & 3.28 \\
\hline 5. & Desire for the College & 24.43 & 3.57 & 22.90 & 4.33 \\
\hline \multicolumn{6}{|c|}{ Disguised-Purpose Dispositional Scales } \\
\hline 6. & Self-Confidence & 32.92 & 3.79 & 30.90 & 5.15 \\
\hline 7. & Decisiveness & 17.58 & 3.11 & 19.20 & 3.45 \\
\hline 8. & Voluntary, avoidable Turnover & 0.33 & 0.47 & 0.59 & 0.49 \\
\hline 9. & Voluntary Turnover & 0.38 & 0.49 & 0.65 & 0.48 \\
\hline
\end{tabular}


Panel B

\begin{tabular}{|c|c|c|c|c|c|c|c|c|c|}
\hline Variable & \multicolumn{9}{|c|}{ Correlations } \\
\hline & $\mathbf{1}$ & $\mathbf{2}$ & $\mathbf{3}$ & $\mathbf{4}$ & $\mathbf{5}$ & $\mathbf{6}$ & $\mathbf{7}$ & $\mathbf{8}$ & $\mathbf{9}$ \\
\hline 1. & 1.00 & & & & & & & & \\
\hline 2. & 0.30 & 1.00 & & & & & & & \\
\hline 3. & 0.02 & 0.04 & 1.00 & & & & & & \\
\hline 4. & 0.13 & 0.09 & 0.06 & 1.00 & & & & & \\
\hline 5. & 0.13 & 0.03 & 0.16 & 0.46 & 1.00 & & & & \\
\hline 6. & 0.11 & 0.02 & 0.06 & 0.51 & 0.47 & 1.00 & & & \\
\hline 7. & 0.15 & -.01 & 0.12 & 0.33 & 0.43 & 0.50 & 1.00 & & \\
\hline 8. & -.21 & -.16 & -.21 & -.17 & -.17 & -.17 & -.22 & 1.00 & \\
\hline 9. & -.05 & -.12 & -.21 & -.18 & -.11 & -.13 & -.22 & 1.00 & 1.00 \\
\hline
\end{tabular}

Appendix Two: Correlations between Voluntary Turnover and Other Variables

\begin{tabular}{|c|c|c|c|c|c|c|c|c|}
\hline & \multicolumn{2}{|c|}{ Step One } & \multicolumn{3}{|c|}{ Step Two } & \multicolumn{3}{|c|}{ Step Three } \\
\hline $\begin{array}{l}\text { Sample and } \\
\text { Study }\end{array}$ & $\mathbf{R}^{2}$ & $\operatorname{Adj} R^{2}$ & $\mathbf{R}^{2}$ & $\operatorname{Adj} R^{2}$ & $\Delta \mathbf{R}^{2}$ & $\mathbf{R}^{2}$ & $\operatorname{Adj} R^{2}$ & $\Delta \mathbf{R}^{2}$ \\
\hline & \multicolumn{2}{|c|}{ Bio-Data } & \multicolumn{3}{|c|}{ Disguised-Purpose } & \multicolumn{3}{|c|}{ Clear-Purpose } \\
\hline Combined & 0.31 & 0.29 & 0.36 & 0.33 & 0.05 & 0.37 & 0.33 & 0.01 \\
\hline \multirow[t]{2}{*}{ Study One } & 0.30 & 0.27 & 0.35 & 0.32 & 0.05 & 0.36 & 0.31 & 0.01 \\
\hline & $* * *$ & & $* * *$ & & $* *$ & $* * *$ & & \\
\hline \multirow[t]{3}{*}{ Study Two } & 0.32 & 0.30 & 0.37 & 0.35 & 0.05 & 0.37 & 0.34 & 0.00 \\
\hline & $* * *$ & & $* * *$ & & $* *$ & $* * *$ & & \\
\hline & \multicolumn{2}{|c|}{ Clear-Purpose } & \multicolumn{3}{|c|}{ Disguised-Purpose } & \multicolumn{3}{|c|}{ Bio-Data } \\
\hline Combined & 0.20 & 0.18 & 0.26 & 0.22 & 0.06 & 0.37 & 0.33 & 0.11 \\
\hline Study One & 0.19 & 0.16 & 0.25 & 0.22 & 0.04 & 0.37 & 0.34 & 0.12 \\
\hline & $* * *$ & & $* *$ & & $* *$ & $* * *$ & & $* * *$ \\
\hline Study Two & 0.21 & 0.20 & 0.25 & 0.22 & 0.04 & 0.37 & 0.34 & 0.12 \\
\hline & $* * *$ & & $* *$ & & $* *$ & **** & & $* * *$ \\
\hline
\end{tabular}

Appendix Three: Logistic Regression of Voluntary Turnover

\begin{tabular}{|c|c|c|c|c|c|}
\hline & Step One & \multicolumn{2}{|c|}{ Step Two } & \multicolumn{2}{|c|}{ Step Three } \\
\hline Study & $\chi^{2}$ & $\chi^{2}$ & $\Delta \chi^{2}$ & $\chi^{2}$ & $\Delta \chi^{2}$ \\
\hline & Bio-Data & \multicolumn{2}{|c|}{ Disguised-Purpose } & \multicolumn{2}{|c|}{ Clear-Purpose } \\
\hline Study One & 16.64 & 22.92 & 6.28 & 24.07 & 1.15 \\
\hline & *** & $* * *$ & $* *$ & *** & \\
\hline Study Two & 27.77 & 39.05 & 11.28 & 39.78 & 0.73 \\
\hline & $* * *$ & $* * *$ & $* *$ & $* * *$ & \\
\hline & Clear-Purpose & \multicolumn{2}{|c|}{ Disguised-Purpose } & \multicolumn{2}{|c|}{ Bio-Data } \\
\hline Study One & 6.67 & 11.26 & 4.59 & 24.07 & 12.81 \\
\hline & $* *$ & $* *$ & $*$ & $* * *$ & $*$ \\
\hline Study Two & 2.51 & 18.01 & 5.50 & 39.78 & 21.77 \\
\hline & $* * *$ & $* * *$ & $*$ & $* * *$ & $* * *$ \\
\hline
\end{tabular}


Appendix Four: Evidence of “d-scores” Across Groups

\begin{tabular}{|l|c|c|c|c|c|}
\hline \multicolumn{1}{|c|}{ Variables } & Race & Race & Race & Gender & Age \\
\hline & White/ Hispanic & White/ Black & Majority/ minority & Male/ Female & Younger/ Older \\
\hline Student Reference & 0.10 & 0.04 & 0.07 & -.32 & -.35 \\
\hline \# Friends \& Family & -.22 & -.15 & -.18 & 0.30 & 0.02 \\
\hline Months at College & 0.10 & 0.21 & 0.16 & -.20 & -.43 \\
\hline Intent to Quit & 0.27 & 0.02 & 0.15 & -.26 & -.21 \\
\hline Enrollment Desire & 0.01 & -.23 & -.11 & -.36 & -.26 \\
\hline Self Confidence & 0.28 & 0.01 & 0.14 & -.13 & -.25 \\
\hline Decisiveness & -.04 & 0.00 & -.02 & -.25 & -.19 \\
\hline Majority Group N & 304 & 304 & 304 & 216 & 378 \\
\hline Minority Group N & 65 & 63 & 128 & 185 & 49 \\
\hline
\end{tabular}

Note: the "d-score" reports the standardized difference between sub-group mean, where (majority mean - minority mean)/pooled standard deviation]. Thus, a positive value indicates the majority group scored higher on the selection tool, whereas a negative value illustrates that the minority group scored higher on the predictor. Younger $=$ participants are less than 40 years old; older $=$ participants are 40 or more years old.

\section{REFERENCES}

1. Abelson, M., 1987. Examination of Avoidable and Unavoidable Turnover, Journal of Applied Psychology, pp. 382-386.

2. Barrick, M. and M. Mount, 1996. Effects of Impression Management and Self-Deception on the Validity of Personality Constructs, Journal of Applied Psychology, pp. 261-272.

3. Barrick, M., M. Mount, and J. Strauss, 1994. Antecedents to Involuntary Turnover due to a Reduction in Force, Personnel Psychology, pp. 515-535.

4. Bernardin, H., 1987. Development and Validation of a Forced Choice Scale to Measure Job-Related Discomfort among Customer Service Representatives, Academy of Management Journal, pp. 162-173.

5. Breaugh, J. and D. Dossett, 1989. Rethinking the Use of Personal History Information: The value of TheoryBased Bio-Data for Predicting Turnover, Journal of Business and Psychology, pp. 371-385.

6. Breaugh, J. and R. Mann, 1984. Recruiting Source Effects: A Test of Two Alternative Hypotheses, Journal of Occupational Psychology, pp. 261-267.

7. Breaugh, J. and M. Starke, 2000. Research on Employee Recruitment: So Many Studies, So Many Remaining Questions, Journal of Management, pp. 405-434.

8. Cascio, W., 1976. Turnover, Biographical Data, and Fair Employment Practice, Journal of Applied Psychology, pp. 576-580.

9. Chatman, J., 1991. Matching People and Organizations: Selection and Socialization in Public Accounting Firms, Administrative Science Quarterly, pp. 459-484.

10. Dean, M., C. Russell, and P. Muchinsky, 1999. Life Experiences and Performance Prediction: Toward a Theory of Bio-Data, in G. Ferris (Ed.), Research in Personnel and Human Resources Management, pp. 245281). Greenwich, CT: JAI Press

11. Feingold, A., 1994. Gender Differences in Personality: A Meta-Analysis, Psychological Bulletin, pp. 429456.

12. Fishbein, M. and I. Ajzen, 1975. Belief, Attitude, Intention, and Behavior: An Introduction to Theory and Research, Reading, MA: Addison-Wesley.

13. Gatewood, R. and H. Feild, 1987. Human Resource Selection, Hinsdale, IL: Dryden Press.

14. Griffeth, R., P. Horn, and S. Gaertner, 2000. A Meta-Analysis of Antecedents and Correlates of Employee Turnover: Update, Moderator Tests, and Research Implications for the Next Millennium, Journal of Management, pp. 463- 488.

15. Hom, P. and R. Griffeth, 1995. Employee Turnover, Cincinnati, OH: South-Western

16. Huselid, M. and N. Day, 1991. Organizational Commitment, Job Involvement, and Turnover: A Substantive and Methodological Analysis, Journal of Applied Psychology, pp. 380-391.

17. Kanungo, R., 1982. Measurement of Job and Work Involvement, Journal of Applied Psychology, pp. 341349 . 
18. Latham. V. and P. Leddy, 1987. Source of Recruitment and Employee Attitudes: An Analysis of Job Involvement, Organizational Commitment, and Job Satisfaction, Journal of Business and Psychology, pp. 230-235.

19. Lee, T., S. Ashford, J. Walsh, and R. Mowday, 1992. Commitment Propensity, Organizational Commitment, and Voluntary Turnover: A Longitudinal Study of Organizational Entry Processes, Journal of Management, pp. 15-32.

20. Lee, T., T. Mitchell, B. Holtom, L. McDaniel, and W. Hill, 1999. Theoretical Development and Extensions of the Unfolding Model of Voluntary Turnover, Academy of Management Journal, pp. 450- 462.

21. Mael, F., and B. Ashforth, 1995. Loyal from Day One: Bio-Data, Organizational Identification, and Turnover among Newcomers, Personnel Psychology, pp. 309-333

22. Mathieu, J. and D. Zajac, 1990. A Review and Meta-Analysis of the Antecedents, Correlates, and Consequences of Organizational Commitment, Psychological Bulletin, pp. 171-194.

23. Mitchell, T. B. Holtom, T. Lee, C. Sablynski, and M. Erez, (2001. Why People Stay: Using Job Embeddedness to Predict Voluntary Turnover, Academy of Management Journal, pp. 1102-1121.

24. Mobley, W., R. Griffeth, H. Hand, and B. Meglino, 1979. Review and Conceptual Analysis of the Employee Turnover Process, Psychological Bulletin, pp. 493-522.

25. Mowday, R., L. Poner, and R. Steers, 1982. Employee Organization Linkages. New York: Academic Press.

26. Ones, D., C. Viswesvaran, and A. Reiss, 1996. Role of Social Desirability in Personality Testing for Personnel Selection: The Red Herring, Journal of Applied Psychology, pp. 660-679.

27. Ones, D., C. Viswesvaran, and F. Schmidt, 1993. Comprehensive Meta-Analysis of Integrity Test Validities: Findings and Implications for Personnel Selection and Theories of Job Performance, Journal of Applied Psychology, pp. 679-703.

28. Owens, W. and L. Schoenfeldt, 1979. Toward a Classification of Persons, Journal of Applied Psychology, pp. 569-607.

29. Pace, L. and L. Schoenfeldt, 1977. Legal Concerns in the Use of Weighted Applications, Personnel Psychology, pp. 159-166.

30. Parsons, C., D. Herold, and M. Leatherwood, 1985. Turnover During Initial Employment: A Longitudinal Study of the Role of Causal Attributions, Journal of Applied Psychology, pp. 337-341.

31. Phillips, J., 1998. Effects of Realistic Job Previews on Multiple Organizational Outcomes: A Meta-Analysis, Academy of Management Journal, pp. 673-691.

32. Rothstein, H., F. Schmidt, F. Erwin, Y. Owens, and C. Sparks, 1990. Biographical Data in Employment Selection: Can Validities be Made Generalizable? Journal of Applied Psychology, pp. 175-184.

33. Rynes, S., 1991. Recruitment, Job Choice, and Post-Hire Consequences: A Call for New Research Directions, In M. Dunnette and L. Hough (Eds.), Handbook of Industrial and Organizational Psychology, pp. 399-444). Palo Alto, CA: Consulting Psychologists Press.

34. Sackell, P., L. Burris, and C. Callahan, 1989. Integrity Testing for Personnel Selection: An Update, Personnel Psychology, pp. 491-529.

35. Salancik, G., 1977. Commitment and the Control of Organizational Behavior, In B. Staw and G. Salancik (Eds.), New Directions in Organizational Behavior, pp.1-54. Chicago: St. Clair Press.

36. Schmidt, F. and J. Hunter, 1998. The Validity and Utility of Selection Methods in Personnel Psychology: Practical and Theoretical Implications of 85 Years of Research Findings, Psychological Bulletin, pp. 262274.

37. Schmill, N., W. Rogers, D. Chan, L. Sheppard, and D. Jennings, 1997. Adverse Impact and Predictive Efficiency of Various Predictor Combinations, Journal of Applied Psychology, pp. 719-730.

38. Tell, R. and J. Meyer, 1993. Job Satisfaction, Organizational Commitment, Turnover Intention, and Turnover: Path Analysis Based on Meta Analytic Findings, Personnel Psychology, pp. 259 -293.

39. Van Maanen, J. and E. Schein, 1979. Toward a Theory of Organizational Socialization, In B. Staw (Ed.), Research in Organizational Behavior, pp. 209-264, Greenwich, CT: JAI Press.

40. Wanous, J. and A. Colella, 1989. Organizational Entry Research: Current Status and Future Directions, in G. Ferris and K. Rowland (Eds.), Research in Personnel and Human Resources Management, pp. 59 -120. Greenwich, CT: JAI Press.

41. Wernimont, P. and J. Campbell, 1968. Signs, Samples, and Criteria, Journal of Applied Psychology, pp. 372376. 
NOTES 